\title{
Sella Turcica
}

National Cancer Institute

\section{Source}

National Cancer Institute. Sella Turcica. NCI Thesaurus. Code C12497.

A bony prominence situated on the upper surface of the body of the sphenoid bone housing the pituitary gland. 